\title{
EXAMINATION OF REPORTING OF INVESTMENTS IN ASSOCIATES AND SUBSIDIARIES IN FINANQAL STATEMENTS WITHIN THE SCOPE OF BOBI FRS AND TFRS
}

DOI: 10.17261/Pressacademia.2020.1233

PAP- V.11-2020(5)-p.22-27

Huseyin Mert ${ }^{1}$, Yusuf Ocalmis ${ }^{2}$

${ }^{1}$ Istanbul Okan University, Department of Accounting and Audit, Istanbul, Turkey. huseyin.mert@okan.edu.tr, ORCID: 0000-0001-5391-7865

2Istanbul Okan University, Department of Accounting and Audit, Istanbul, Turkey. yocalmis@stu.okan.edu.tr, ORCID: 0000-0002-6738-2846

To cite this document

Mert, H., Ocalmis, Y. (2020). Examination of reporting of investments in associates and subsidiaries in financial statements within the scope of BOBi FRS and TFRS. PressAcademia Procedia (PAP), V.11, p. 22-27

Permanent link to this document: http://doi.org/10.17261/Pressacademia.2020.1233

Copyright: Published by PressAcademia and limited licensed re-use rights only.

\section{ABSTRACT}

Purpose- Subsidiary and subsidiary investments can be reported in different ways in the financial statements of businesses reporting according to BOBI FRS or TFRS. The aim of this study is to analyze the differences in implementation and their effects on the results of operations in reporting of subsidiary and subsidiary investments in terms of BOBI FRS and TFRS.

Methodology- The financial statements of the same company prepared under BOBI FRS and TFRS were compared.

Findings- A difference was determined between equity and cost methods in terms of presentation differences and values of investments. While the operating results of the investment are not reflected in the financial statements in the cost method, the operating results of the investment in the equity method are determined to be reflected in the financial statements.

Conclusion- Standardizing the implementation of the equity method in reporting investments in associates and subsidiaries will eliminate the differences as well as providing reliable information.

Keywords: BOBI FRS, TFRS, equity method.

JEL Codes: M40, M41, M42

\section{IŞTIRAK VE BAĞLI ORTAKLIK YATIRIMLARININ FINANSAL TABLOLARDA RAPORLANMASININ BOBi FRS VE TFRS KAPSAMINDA INCELENMESI}

\section{ÖZET}

Amaç- İştirak ve bağlı ortaklık yatırımları, BOBi FRS veya TFRS'ye göre raporlama yapan işletmelerin finansal tablolarında farklı yöntemlerle raporlanabilmektedir. Bu çalışmanın amacı, BOBi FRS ve TFRS açısından iştirak ve bağlı ortaklık yatırımlarının raporlanmasındaki uygulama farklılıklarını ve faaliyet sonuçlarına olan etkilerini çeşitli varsayımlar altında analiz etmektir.

Yöntem- Sanayi sektöründe faaliyet gösteren ve finansal tablolarını BOBi FRS kapsamında hazırlayan şirketin, 2018 ve 2019 yılları fina nsal tabloları TFRS kapsamında hazırlanarak sonuçlar karşılaştırılmıştır. Böylece iştirak ve bağlı ortaklık yatırımlarının raporlanmasının, finan sal tablolar ve sonuç hesaplarına olan etkilerini BOBi FRS ve TFRS'ye göre görmek mümkün olmuştur.

Bulgular- Özkaynak ve maliyet yöntemleri arasında sunum farklılığı ile yatırımların değerleri açısından farklılık tespit edilmiştir. Maliyet yönteminde yatırımın faaliyet sonuçları finansal tablolara yansımazken, özkaynak yönteminde yatırımın faaliyet sonuçları fina nsal tablolara yansıdığı tespit edilmiştir.

Sonuç- BOBI FRS ve TFRS uygulamalarında iştirak ve bağlı ortaklık yatırımları finansal tablolarda farklı yöntemlerle raporlanabilmektedir. İştirak ve bağlı ortaklık yatırımlarının finansal tablolarda raporlanmasında özkaynak yöntemi uygulanmasının standart hale getirilmesi, farklııkları ortadan kaldıracağı gibi güvenilir bilgi sunumu da sağlanmış olacaktır.

Anahtar Kelimeler: BOBI FRS, TFRS, equity method.

JEL Kodları: M40, M41, M42 


\section{Gíriş}

Ulusal ve uluslararası artan rekabet ortamında işletmeler faaliyetlerine devam edebilmek ve sürekliliklerini sağlayıp büyüyebilmek için çok çeşitli stratejik kararlar vermek durumunda kalırlar. Bu kararlardan olan başka şirketlere yapılan yatırımlarla yatı rımcı şirketler, yatııım yaptıkları şirketin finansal, yönetim ve stratejik kararlarında söz sahibi olmak, onları kontrol altına almak ya da onların faaliyetlerinden kar elde etmeyi amaçlarlar.

İşletmenin üzerindeki etki derecesine göre iştirak yatıııları, menkul kıymet yatırımı, iştirak yatııımı, bağlı ortaklık yatııım ve diğer uzun vadeli yatııımlar olarak sınıflandırımaktadır. TMS 28 İştiraklerdeki ve iş Ortaklıklarındaki Yatırımlar standardı ile BOBi FRS Bölüm 10'da iştiraklerin, ana ortaklık niteliğinde ve konsolide finansal tablolar haricinde iştiraki bulunan bir yatırımcının finansal tablolarında raporlanması konu edilmiştir.

Bu çalışmada iştirakler ve bağı ortaklıkların finansal tablolarda raporlanmasının BOBi FRS ve TFRS kapsamında incelemesi yapılmış, maliyet ve özkaynak yöntemlerinden kaynaklanan farklar tespit edilmiş ve sonuçlarının finansal tablo kullanıcılarına ilave bilgiler sunulması hedeflenmiştir.

\section{TEMEL KAVRAMLAR}

Yatırımcı şirketlerin iştirak paylarını elde bulundurma nedenleri, alım satım amaçlı veya satılıaya hazır finansal varlık olarak olabileceği gibi stratejik bir yatırımda olabilir. Yatııımdaki önemli etkiye veya kontrol gücüne göre yatııımlar farklı sınıflandırılır ve fin ansal tablolara alınma yöntemi, ilgili raporlama standartlarına göre değişiklik gösterir. İştirak yatırımlarının finansal (mali) duran varlıklar olarak sınıflandııılması uzun vadeli yatırım olmalarından kaynaklanmaktadır.

\section{1. İştirak Kavramı}

TMS 28 iştiraklerdeki ve İş Ortaklıklarındaki Yatırımlar standardında iştirak tanımı; üzerinde önemli etkinin bulunduğu işletme olarak tanımlanmıştır (TMS 28 p.3.).

Önemli etki kavramı, yatırım yapılan işletmenin faaliyet ve finansal politikalarının belirlenmesi, işletmenin kararlarına katılma gücünü ifade edip, politikaları tek başına kontrol etme gücü veya bir başka taraf ile müşterek kontrol etme gücünü ifade etmemektedir (Kıymetli Şen, Üçoğlu ve Terzi 2015: 104).

İştirak yatırımları BOBi FRS' de yatırım yapan işletmenin üzerinde önemli etkisinin bulunduğu, adi ortaklık gibi tüzel kişiliği olmayan işletmeler de dahil olmak üzere, müşterek girişim veya bağı ortaklık niteliğinde olmayan işletmeler olarak tanımlanmaktadır (BOBi FRS, Par. 10.2).

\section{2. Önemli Etki}

TMS 28 İştiraklerdeki ve İş Ortaklıklarındaki Yatırımlar standardında önemli etki: "Yatırım yapılan işletmenin faaliyet ve finansal politikalarının belirlenmesi ve kararlarına katılma gücü olarak ifade edilip, bu politikaları tek başına ya da bir başka taraf ile müşterek k ontrol etme gücünü ifade etmemektedir." olarak tanımlanmaktadır (TMS 28, p.3.).

BOBі FRS' deki tanımda önemli etki kavramı "yatırım yapılan şirketin faaliyet ve finansal politikalarının karar alma süreçlerine ka tılma gücü olarak ifade edilip, bu politikaları tek başına kontrol etme ya da başka taraf ile müşterek kontrol etme gücü değildir." olarak tanımlanmaktadır (BOBi FRS, Bölüm 10.3.).

Tablo 1: Karşılaştırma - İştirak Yatırımları

\begin{tabular}{|c|c|c|c|}
\hline & BOBI FRS & MSGUT & TFRS \\
\hline İştirak Tanımı & Önemli etki var & $\% 10-\% 50$ arasında oy hakkı & BOBI FRS ile uyumlu \\
\hline \multirow[b]{2}{*}{ İştirakin Ölçümü } & $\begin{array}{l}\text { Konsolidasyonda: } \\
\text { - Özkaynak yöntemi }\end{array}$ & \multirow[b]{2}{*}{ Alış bedeli } & $\begin{array}{l}\text { Konsolidasyonda: } \\
\text { BOBi FRS ile uyumlu }\end{array}$ \\
\hline & $\begin{array}{l}\text { Münferit finansal tablolarda: } \\
\text { - Maliyet bedeli } \\
\text { - Özkaynak yöntemi }\end{array}$ & & $\begin{array}{l}\text { Münferit finansal tablolarda: } \\
\text { - Maliyet bedeli } \\
\text { - Özkaynak yöntemi } \\
\text { - Gerçeğe uygun değer }\end{array}$ \\
\hline
\end{tabular}

Kaynak: (3. Oturum Slayt 38) KGK - BOBi FRS Sunum

\subsection{Kontrol Gücü}

Yatırımcı işletme, yatırım yaptığı şirketin getirilerini etkileyen faaliyetlerini önemli ölçüde etkileyebiliyorsa ve bunları yönetebilme haklarına sahipse, yatırım yaptığı şirket üzerinde güce sahiptir (TMS 28, p.5.). 
Tablo 2: Kontrolün Değerlendirilmesi

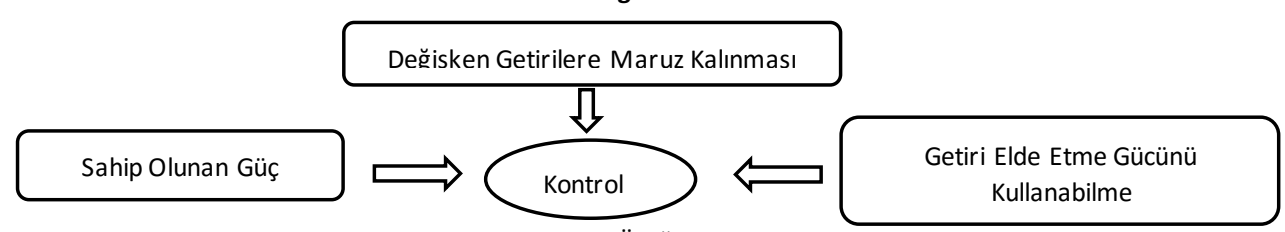

Kaynak: Kıymetli Şen, Üçoğlu ve Terzi.

Kontrol gücü, iştirak üzerinde bir etki icra etmek ve iştirakin ticari politikalarını belirleme gücüne sahip olarak tanımlana bilir. Kontrol eden ve kontrol edilen ilişkisi varsa bu şirketler ilişkili şirket olarak tanımlanabilmektedir (Eyüpgiller, S. 2012: 8).

TFRS 10' da kontrol gücü; yatırım yapan işletmenin, iştirakiyle olan ilişkisinden dolayı değişken getirilere maruz kalması vey a bu getirilerde hak sahibi olması ve bu getirileri iştirakinin üzerindeki gücüyle etkileme imkânına sahip olduğu durumlarda, iştirakini kontrol etmektedir şeklinde ifade edilmektedir.

\subsection{Bağlı Ortaklık}

Bağlı ortaklık, "Başka bir işletme tarafından kontrol edilen bir işletmedir." şeklinde tanımlanmaktadır (TFRS 10). Yatırımın üzerinde güce sahip olunması, yatırımdan dolayı değişken getirilere maruz kalma ve bu getirilerin miktarını etkileyebilecek gücü kullanabilme dur umlarında kontrol edilebilme kavramı söz konusu olabilmektedir.

\section{MUHASEBELEŞTIRME VE RAPORLAMA}

İlk kayda almada iştirakler, maliyet bedeli üzerinden ölçülmektedir (BOBi FRS, Par. 10.7.). TMS 28 de benzer şekilde elde etme maliyeti ile muhasebeleştirilir ifadesi yer almaktadır. Sonraki ölçümde münferit finansal tablolar için maliyet yöntemi veya özkaynak yöntemlerinden biri seçilir, konsolide de ise özkaynak yöntemi uygulanır (Ataman, Gökçen 2017: 135)

Tablo 3: İ̧̧tirak Yatırımlarının Ölçümü

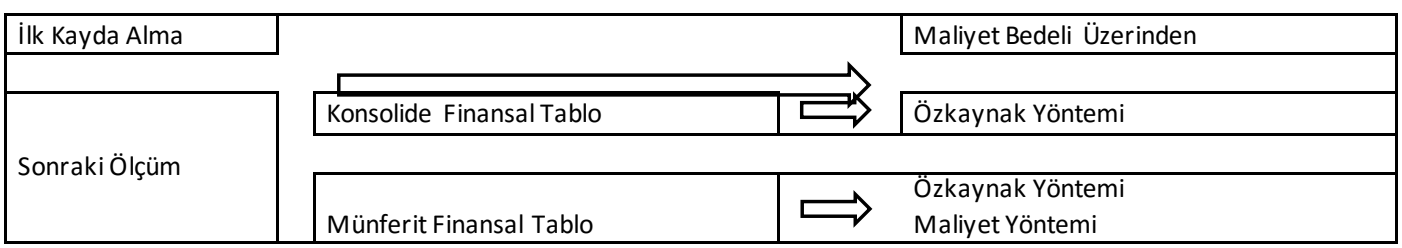

Kaynak: (3. Oturum Slayt 30) KGK BOBi FRS Sunum

\subsection{Maliyet Yöntemi}

TMS 28 Işstiraklerdeki ve İş Ortaklıklarındaki Yatırımlar standardında iştirakler, ilk olarak elde edildiği tarihte elde etme maliyeti ile muhasebeleştirilir. Satın alma fiyatı, yasal giderler ve diğer satın alma ile ilgili işlem giderleri maliyeti oluşturmaktadır. Değer düşüklüğüne uğraması durumunda maliyet bedelinden değer düşüklüğü zararı indirilir ve kalan tutar üzerinden raporlanır (Karapınar ve Efla tun 2019: 182)

\section{2. Özkaynak Yöntemi}

TFRS 28 İştiraklerdeki ve İş Ortaklıklarındaki Yatırımlar standardında özkaynak yöntemi; yatırımın başlangıçta elde etme maliyeti ile muhasebeleştirildiği ve bu tutarın iştirakin net varlıklarında yatırımcı işletmenin payına düşen kısmı yansıtacak şekilde düzeltildiği bir yöntemdir. Yatırımcı işletmenin kar veya zararı, iştirakin kar veya zararından kendisine düşen payı; yatırımcı işletmenin diğer kapsamlı karı, yatırım yapılan işletmenin diğer kapsamlı karından kendisine düşen payı da içermektedir (TFRS 28, p.10.). Özkaynak yönteminde, gerçeğe uygun değerdeki değişimlerle ilgili olarak yatırım hesabında bir düzeltme yapılmaz (Ketz 2003: 56).

Özkaynak yönteminde, grup içi işlemlerden doğan kar veya zararın tek bir kalem olarak elimine edilmesi, gelir ve gider unsurları birleştirilmediği için gereklidir (Örten, Kaval ve Karapınar 2020; 642).

Uygulama: Saf Çelik Anonim Şirketi'nin 55\% oranında pay sahibi olduğu Profil A.Ş. 2018 yılını 350.500. -TL kar ile tamamlamıştır. Profil A.Ş. performansını artırarak 2019 yılını 475.300.TL kar ile tamamlamıştır. Profil A.Ş. 2018 ve 2019 yıllarında kar dağıtmamıştır. Saf Çelik A.Ş. 2019 yılı içerisinde iştirak yatırımlarını artırarak 05.02.2019 tarihinde Demir A.Ş.' nin 40\% payını ve 15.04.2019 tarihinde Metal A.Ş.'nin 45\% payını gerçeğe uygun değerinde satın almıştır. Ödemeleri banka aracılığı ile gerçekleştirmiştir.

Açıklamalar: Saf Çelik A.Ş. BOBi FRS büyük işletme kapsamında olmadığından raporlamasınımünferit finansal tablo olarak seçmiştir. Eğer şirket TMS/TFRS kapsamında veya BOBi FRS büyük işletme kapsamında olsaydı finansal tablolarını konsolide olarak raporlamak zorunda 
olacaktı. Bu durumda bağı ortaklı̆̆ını finansal tablolarında konsolide edecek, iştirak yatııılarını ise özkaynak yöntemine g öre raporlaması gerekecekti.

*Çalışmamızda Saf Çelik A.Ş.'nin münferit finansal tablolarında maliyet ve özkaynak yöntemlerine göre raporlama sonuçları incelenmiştir.

2018 yilı yapılması gereken kayıtlar

\section{Maliyet Yöntem}

Maliyet yöntemine göre yapılması gereken bir muhasebe kayd yoktur.

\section{Özkaynak Yöntemi}

$-31.12 .2018$

242 işTiRAKLER

192.775

242.01 Profil A.Ş.

649 DíĞER OLĞ. GEL./KAR

192.775

Profil A.Ş. 31.12.2018 net kar bildirimi

\section{9 yilı yapılması gereken kayıtlar}

\section{Maliyet Yöntemi}

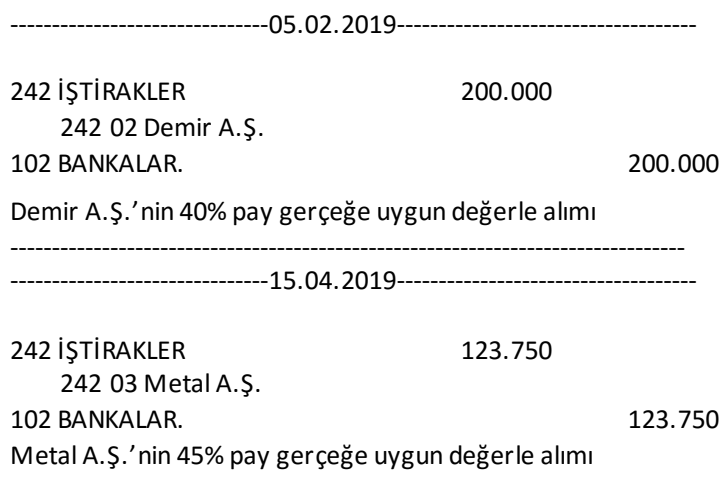

İştiraklerin faaliyet sonuçları için Maliyet Yönteminde bir kayıt yapılmamaktadır.

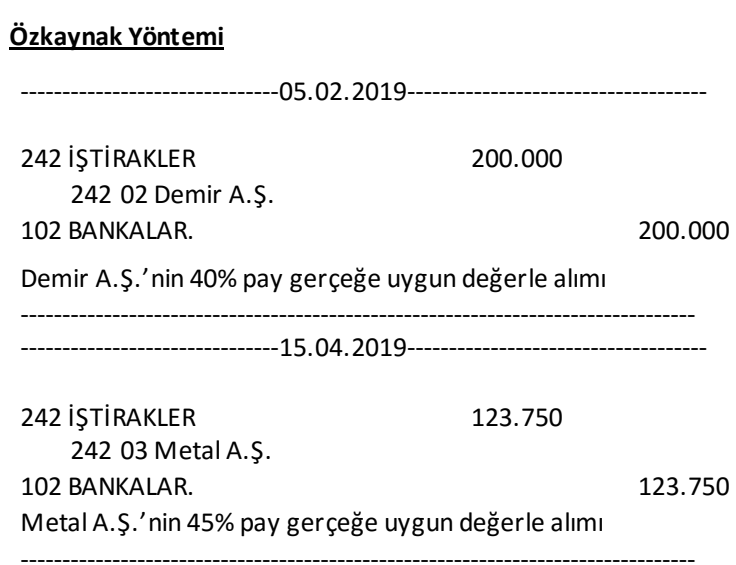

İştiraklerin faaliyet sonuçları Özkaynak Yöntemine göre iştirakler hesabında payları oranında kayıt gerektirmektedir.

-31.12.2019--
242 IŞTIRAKLER
261.415

24201 Profil A.Ş.

649 Dỉ̆. OLĞ. GEL./KAR.

261.415

Profil A.Ş. 31.12.2019 tarihinde net kar bildirimi

659 DiĞ. OLĞ. GID./ZARARLAR
242 IŞTIRAKLER

24202 Demir A.Ş.

Demir A.Ş. 31.12.2019 tarihinde net zarar bildirimi

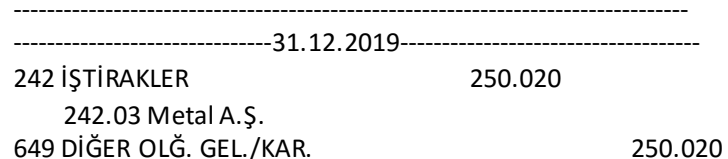

Metal A.Ş. 31.12.2019 tarihinde net kar bildirimi

*Bağı ortaklık veya iştirak yıl sonundan önce geçmiş yıl karının dă̆ııım kararını almış olsaydı, yatııımcı işletme kendi finansal tablolarında temettü gelirini tahakkuk esası gereği kayıt edecekti (Elliott 2007: 572). 
İştiraklerin Performans Durumları

\begin{tabular}{|l|l|l|l|l|l|l|}
\hline Yıllar & & Sermaye & Elde etme maliyeti & Pay Oranı \% & Kar Zarar & $\begin{array}{l}\text { Iştiraklerin } \\
\text { Özkaynakları }\end{array}$ \\
\hline 31.12 .2018 & Profil A.Ş. & 250.000 & 87.500 & $55 \%$ & 350.500 & 600.500 \\
\hline & & & & & & \\
\hline 31.12 .2019 & Profil A.Ş. & 250.000 & 37.500 & $55 \%$ & 475.300 & 1.075 .800 \\
\hline 31.12 .2019 & Demir A.Ş. & 500.000 & 200.000 & $40 \%$ & $(475.500)$ & 24.500 \\
\hline 31.12 .2019 & Metal A.Ş. & 275.000 & 112.500 & $45 \%$ & 555.600 & 830.600 \\
\hline
\end{tabular}

Maliyet ve Özkaynak Yöntemlerine göre Finansal Durum Tabloları

\begin{tabular}{|c|c|c|c|}
\hline \multicolumn{2}{|l|}{$\begin{array}{l}\text { Saf Çelik Anonim Şirketi } \\
\text { Maliyet Yöntemi }\end{array}$} & \multicolumn{2}{|l|}{$\begin{array}{l}\text { Saf Çelik Anonim Şirketi } \\
\text { Özkaynak Yöntemi }\end{array}$} \\
\hline Finansal Durum Tablosu & 31.12 .2018 & Finansal Durum Tablosu & 31.12.2018 \\
\hline 242.01 Profil A.Ş. & 87.500 & 242.01 Profil A.Ş. & 330.275 \\
\hline Maliyet yöntemiyle değerlenen yatırımlar & 87.500 & Özkaynak yöntemiyle değerlenen yatırımlar & 330.275 \\
\hline Finansal Durum Tablosu & 31.12.2019 & Finansal Durum Tablosu & 31.12.2019 \\
\hline 242.01 Profil A.Ş. & 37.500 & 242.01 Profil A.Ş. & 591.690 \\
\hline 242.02 Demir A.Ş. & 200.000 & 242.02 Demir A.Ş. & 9.800 \\
\hline 242.03 Metal A.Ş. & 112.500 & 242.03 Metal A.Ş. & 373.770 \\
\hline Maliyet yöntemiyle değerlenen yatırımlar & 350.000 & Özkaynak yöntemiyle değerlenen yatırımlar & 975.260 \\
\hline
\end{tabular}

Maliyet yöntemine göre iştiraklerin 31.12.2019 tarihindeki bilanço değeri 350.000. -TL'dir. Özkaynak yöntemine göre 31.12.2019 tarihinde iştiraklerin bilançodaki değeri 975.260.-TL'dir. Maliyet ve Özkaynakyöntemleri arasındaki fark 625.260.-TL'dir.

Maliyet yönteminde yatırımın değerinin, iştiraklerin faaliyet sonuçlarını yansıtamadığı görülmektedir. Maliyet yönteminin kullanılması, yatırımcıların faaliyetleri en azından kısmen raporlayan işletmenin (yatırımcılar) yönetim kararları ve işletme becerilerinin göstergesi olan bir işletmeye ilgisinin ekonomik gerçekliğini yansıtmayacaktır (Epstein B. J. ve Jermakowicz, E. K. 2007: 353).

\section{SONUÇ VEÖNERILER}

Standartlar karşılaştırmalı olarak incelendiğinde iştirak yatırımlarının muhasebeleştirilmesi ve raporlanması, özel bir standart olarak yer alıp, oran ve değerleme hükümleri açısından farklılık göstermektedir. Maliyet yöntemi uygulandığında sadece dağıtılan temettüler finansal tablolara yansırken, iştirakin performansını gösteren kar veya zarar durumu finansal tablolara yansımayacaktır.

BOBI FRS büyük işletme kapsamında olmayan işletmelerin, münferit finansal tablo uygulamalarında, maliyet yöntemini tercih edebilmesi, yatırımc şirketlere iştiraki üzerindeki önemli etkisini kullanarak kar payı dağıtımını erteletmesi veya ihtiyaç duyduğunda kar dağıımını gerçekleştirmesi imkânını sunmaktadır. Bu durumda yatırımcı şirket kendi faaliyet sonuçlarındaki düşük performansını, iştirakteki kar dağıtımı kararını aldırarak kapatabilecektir.

Çalışmadaki uygulama sonuçları değerlendirildiğinde, özkaynak yöntemi iştiraklerin faaliyet sonuçlarını hesaplara tam olarak yansıttığından, iştiraklerden kaynaklanacak fayda ve zararlar takip edilebilmektedir. Finansal tablo kullanıcıları için iştiraklerin faaliyet sonuçlarını görebilmek yapmış oldukları yatırımları için karar almalarında önemli bir durumdur.

İştirak yatııımlarının finansal tablolarda raporlanmasında özkaynak yöntemi uygulanmasının standart hale getirilmesi, farklılıkları ortadan kaldıracağı gibi güvenilir bilgi sunumu da sağlanmış olacaktır.

\section{KAYNAKÇA}

Ataman, B. ve Gökçen G. (2017). Büyük ve Orta Boy İşletmeler İçin Finansal Raporlama Standardı (BOBi FRS) Uygulamaları. İstanbul. Beta.

Elliott, B ve Elliott, J. (2007). Financial Accounting and Reporting, 11th Edition, England: Pearson Education Limited.

Epstein B. J. ve Jermakowicz, E. K. (2007). Wiley IFRS 2007: Interpretation and Application of International Financial Reporting Standarts, John Wiley \& Sons, New Jersey.

Eyüpgiller, S. Saygın 2012. Şirketler Topluluğunda Konsolidasyon. Ankara. Detay Yayıncılık.

Karapınar, A ve Eflatun A. O. 2019. BOBi FRS Uygulama ve Yorumları. Ankara. Gazi Kitapevi. 
Kıymetli Şen, Üçoğlu ve Terzi 2015. Uluslararası/Türkiye Finansal Raporlama Standartları Açısından Konsolide Finansal Raporlama. İstanbul. Ekin Yayınevi.

Ketz, J. E. (2003), Hidden Financial Risk, Understanding Off-Balance Sheet Accounting, John Wiley \& Sons, New Jersey.

Örten, R., Kaval H. ve Karapınar A. 2020. Türkiye Muhasebe - Finansal Raporlama Standartları Uygulama ve Yorumları 2020 TMS -TFRS. Ankara. Gazi Kitapevi.

Özbirecikli, Mehmet, Kıymetli Şen İlker, Tüm Kayahan (2017). Uygulamaya Dönük Örnekli Açıklamalarla Büyük ve Orta Boy Işsletmeler İçin Finansal Raporlama Standardı. İstanbul. Detay Yayıncılık.

https://kgk.gov.tr/Portalv2Uploads/files/PDF\%20linkleri/BOBi frs.PDF

https://kgk.gov.tr/Portalv2Uploads/files/Duyurular/v2/TMS/TMS 2020/TMS\%2028.pdf

https://www.ipsasb.org/publications/ipsas-36-investments-associates-and-ioint-ventures-1

https://www.mevzuat.gov.tr/MevzuatMetin/1.5.6102.pdf 